https://doi.org/10.30910/turkjans.767790

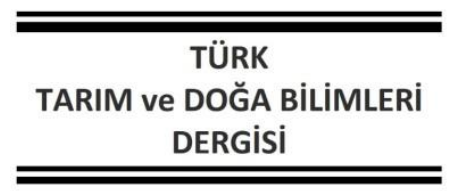

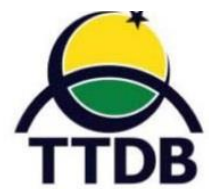

www.dergipark.gov.tr/turkjans

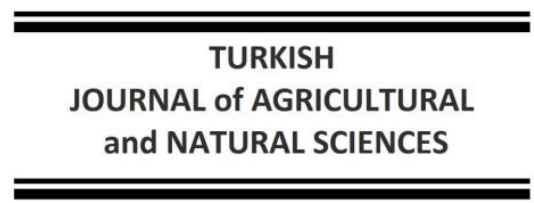

Araştırma Makalesi

\title{
Bazı Tıbbi Bitki Ekstraktlarının Mısır, Soya ve Ayçiçeği Tohumlarının Çimlenmesi ve Fide Gelişimi Üzerine Allelopatik Etkisi ${ }^{*}$
}

\author{
Esra YILDIZ1 ${ }^{1}$, Mehmet Muharrem ÖZCAN² , Şevket Metin KARA ${ }^{2^{*}}$ \\ ${ }^{1}$ Ordu Üniversitesi Fen Bilimleri Enstitüsü Tarla Bitkileri Anabilim Dalı, Ordu \\ ${ }^{2}$ Ordu Üniversitesi Ziraat Fakültesi Tarla Bitkileri Bölümü, Ordu \\ *Sorumlu Yazar: smkara58@hotmail.com
}

\section{Geliş Tarihi: 10.07.2020 Düzeltme Geliş Tarihi: 23.10.2020 Kabul Tarihi: 23.10.2020}

\section{Öz}

Bitkiler arasındaki allelopatik ilişkiler doğal ortamlarda farklı ekosistemlerin oluşumu, biyolojik çeşitliliğin düzenlenmesi ve sürdürülebilirliği yönünden büyük öneme sahiptir. Özellikle tıbbi bitkilerde fazla sayı ve çeşitlilikte sentezlenen bazı biyokimyasallar çevredeki diğer bitkilerin büyüme ve gelişmesi üzerine teşvik edici veya engelleyici etki yapmaktadırlar. Bu araştırma Karadeniz Bölgesi'nde doğal yayılış gösteren bazı tıbbi bitki ekstraktlarının mısır, soya ve ayçiçeği tohumlarının çimlenmesi ve fide gelişimi üzerine allelopatik etkisini belirlemek amacıyla yürütülmüştür. Araştırmada farklı dozlarda (0, \%5, \%10 ve \%20) ısırgan ve karalahana ile mor ve sarı çiçekli ormangülü yaprak ekstraktlarının mısır, soya ve ayçiçeği tohumlarının çimlenme ve fide gelişimine etkileri incelenmiştir. Tüm bitkilerde ekstrakt dozlarının artışına paralel olarak mısır, soya ve ayçiçeği tohumlarının çimlenme ve fide gelişiminde ekstrakt uygulanmayan kontrol tohumlarına göre çok önemli azalmalar ortaya çıkmıştır. Artan ekstrakt dozlarının çimlenme ve fide gelişimini engelleyici etkisi tıbbi bitkilere göre büyük ölçüde değişim göstermiş olup, ısırgan ve karalahana ekstraktlarının engelleyici etkisi mor ve sarı çiçekli orman gülüne göre daha fazla olmuştur. Bütün test bitkilerinde tıbbi bitkilere ait yaprak ekstraktlarının çimlenme ve fide gelişimini engelleyici etkisi ısırgan > karalahana > mor çiçekli ormangülü > sarı çiçekli ormangülü şeklinde azalan bir sıralama izlemiştir. Isırgan ve karalahana yaprak ekstraktlarının \%20'lik dozları soya ve ayçiçeği tohumlarında çimlenme ve fide gelişimini tamamen engellemiştir. Sonuç olarak, bu araştırma bulguları ısırgan ve karalahana yaprak ekstraktlarının soya, mısır ve ayçiçeği tohumlarının çimlenme ve fide gelişimi üzerine çok önemli allelopatik etkiye sahip olduğunu ortaya koymuştur.

Anahtar Kelimeler: Allelopati, Isırgan, Karalahana, Ormangülü, Yaprak ekstraktı

\section{Allelopathic Effect of Some Medicinal Plant Extracts on Seed Germination and Seedling Growth of Maize, Soybean and Sunflower}

\begin{abstract}
Allopathic effects among plants are of considerable importance in existence of different ecosystems, regulating of biodiversity and sustainability in natural environments. Certain biochemicals especially synthesized in medicinal plants inhibit or promote the growth and development of other plants in surrounding environment. This study was carried out with the aim of determining allopathic effect of certain medicinal plants widespread in the Black Sea region of Turkey. The effects of leaf extracts of nettle, black cabbage and rhododendrons with purple and yellow flower in different concentrations (0,5\%, 10\%, and $20 \%$ ) on seed germination and seedling growth of maize, soybean and sunflower were investigated. In accordance with increasing extract doses, very significant decreases were observed in seed germination and seedling growth of maize, soybean and sunflower as compared to the control treatment. The inhibitory effect of increasing extract doses varied rather significantly according to plant source of the extract and the inhibitory effects of nettle and black cabbage were much pronounced than those of purple and yellow flowered rhododendron. In all test plants, inhibitory effects of the leaf extracts on seed germination and seedling growth were in the order of nettle $>$ black cabbage $>$ purple flowered rhododendron $>$ yellow flowered rhododendron. The treatments of
\end{abstract}


$20 \%$ nettle and black cabbage leaf extracts completely inhibited seed germination and seedling growth of soybean and sunflower. In conclusion, these results indicate that leaf extracts of nettle and black cabbage have strong allopathic effects on seed germination and seedling growth in maize, soybean and sunflower.

Key Words: Allopathy, Black cabbage, Leaf extract, Nettle, Rhododendron

\section{Giriş}

Son yıllarda sürdürülebilir kalkınma anlayışının önem kazanmasıyla birlikte bitkilerin allelopatik etkilerinin yeniden merak uyandırdığı ve bu konuda yapılan araştırmaların giderek artmakta olduğu dikkati çekmektedir. Aslında insanoğlu özellikle tıbbi bitkilerden elde edilen ekstrelerin ve uçucu yağların allelopatik etkilerinden yıllardır faydalanmaktadır (Alam ve ark., 2001). Doğal ortamlarda farklı ekosistemlerin oluşumu, biyolojik çeşitliliğin düzenlenmesi ve sürdürülebilirliği, çevre sağlığının korunması ve gıda güvenliğinin sağlanması açısından allelopatinin önemi büyüktür (Farooq ve ark., 2013). Buna uygun olarak bitkisel üretimde yabancı ot ve zararlı kontrolünde tıbbi bitkilerin allelopatik etkilerinden yararlanma imkanları üzerindeki çalışmaların hız kazandığı görülmektedir (Uludağ ve ark., 2006; Macias ve ark., 2007; Cummings ve ark., 2012; Trezzi ve ark., 2016).

Allelopati terimi bitkinin, çevreye saldığı kimyasal bileşiklerle, aynı ekosistemdeki başka bir canlıyı doğrudan veya dolaylı şekilde olumlu veya olumsuz olarak etkilemesi olarak tanımlanabilir (Gürsoy ve ark., 2013). Allelopati canlılar arasındaki engelleyici ve teşvik edici ilişkileri kapsamakla birlikte, çoklukla olumsuz etkileşimleri ifade etmek için kullanılmaktadır (Bhadoria, 2011). Bitkilerde allelopati ve doğal savunma mekanizmaları aslında bir bütünün ayrılmaz iki parçasıdır. Bitkilerde özellikle stres şartlarında sentezlenen ve fitotoksin olarak görev yapan sekonder metabolitlerin önemli allelopatik potansiyele sahip olduğu bilinmektedir. Bitkilerin en önemli kimyasal savunma ajanları konumunda olan fitotoksinler başka türden bitki tohumlarının ve yabancı otların çimlenmesini ve büyüyüp-gelişmesini engellerler, zararlı böcekleri uzak tutarlar ve patojenik mikroorganizmaların çoğalma-büyüme ve gelişmesine engel olurlar (Singh ve ark., 2001; Farooq ve ark.,2011; Cheng ve Cheng, 2015).

Allelopatik etki gösteren sekonder metabolitler kök, yaprak, gövde, çiçek ve tohum gibi tüm bitki aksamında bulunabilirler ve delişme dönemlerine göre miktar ve içerikleri değişebilir. Bitkilerde sentezlenen allelokimyasalların atmosfer ve toprağa karışması buharlaşma, çiğ veya yağmurla toprak üstü bitki organlarından yıkanma, kök salgıları ve bitki artıklarının ayrışmasıyla olur
(Weston ve Duke, 2003). Sekonder metabolitlerin allelopatik etkileri bitki türüne, gelişme dönemine, bitki organına, konsantrasyonuna ve içerdiği bileşenlere bağlı olarak büyük farklılık gösterebilmektedir (Batish ve ark., 2001; Singh ve ark., 2003; Duke, 2010).

Aslında güçlü allelopatik özelliklere sahip olan bitki sayısı çok fazla olmamakla birlikte, özellikle yüksek dozlarda çoğu bitki allelopatik etki gösterebildiği için, bitkilerin allelopatik potansiyelinin laboratuvar ve tarla denemeleriyle belirlenmesi çok önemlidir (Fujii ve ark., 2003). Bu kapsamda Türkiye'de yürütülen bir çalışmada, aktarlardan alınan 55 familyadan 126 tıbbi bitki türünden 40 kadarının marulda kök ve sürgün gelişmesini engellediği belirlenmiştir (Ozkan ve ark., 2019). Benzer şekilde çeşitli tıbbi bitkilerden elde edilen uçucu yağların veya ekstraktların yabancı otlar ve kültür bitkilerinin çimlenme ve fide gelişimlerini engellediğini gösteren çalışmalar vardır (Önen ve ark., 2002; Arslan ve ark., 2005; Turker and Usta, 2006; Atak ve ark., 2016). Ancak literatürde Türkiye'nin Karadeniz Bölgesi'nde yaygın olarak üretilen karalahana ve bölgede doğal olarak geniş bir yayılış gösteren ısırgan, mor çiçekli ormangülü ve sarı çiçekli ormangülü bitkilerinin allelopatik potansiyelinin incelendiği herhangi bir çalışmaya rastlanılmamıştır. Bu konudaki bilgi eksikliğini gidermeye yönelik ilk araştırma durumunda olan bu çalışma karalahana, ısırgan, sarı çiçekli ve mor çiçekli ormangülü yaprak ekstraklarının mısır, soya ve ayçiçeği tohumlarının çimlenme ve fide gelişimi üzerine allelopatik etkilerinin belirlenmesi amacıyla yürütülmüştür.

\section{Materyal ve Metot}

Çalışmada Karadeniz Bölgesi'nde yaygın olarak yetiştirilen karalahana (Brassica oleracea var. viridis, Brassicaceae) ve doğal florada geniş yayılış gösteren ısırgan (Urtica dioica L., Urticaceae), mor ve sarı çiçekli ormangülü (Rhododendron ponticum, Rhododendron luteum, Ericaceae) bitkileri ekstrakt kaynağı olarak kullanılmıştır. Bu bitkilerin yaprak ekstraktlarıyla muamele edildikten sonra çimlendirme denemelerine alınan ayçiçeği, mısır ve soya tohumları Samsun'da bulunan Karadeniz Tarımsal Araştırma Enstitüsü'nden temin edilmiştir.

Ordu ili Ünye ilçesinde üretici tarlasından temin edilen karalahana ve doğal ortamdan toplanan ısırgan, mor ve sarı çiçekli ormangülü yaprakları gölgede soldurulup, laboratuvarda 
kurutulmuş ve öğütücüde öğütülerek toz haline getirilmiştir. Yaprak ekstraktları 0 (kontrol, distile su), $\% 5, \% 10$ ve $\% 20$ olacak şekilde 4 farklı dozda hazırlanmıştır. Yaprak özütleri \%5, \%10 ve \%20 dozları için sırasıyla $25 \mathrm{~g}, 50 \mathrm{~g}$ ve $100 \mathrm{~g}$ kurutulupöğütülmüş örneklerin $500 \mathrm{ml}$ saf su içerisinde normal oda koşullarında 24 saat bekletilmesiyle hazırlanmıştır. Bu süre sonunda, özütlerin sıvı ve katı kısımları 4 katlı tülbentle süzülerek ayrılmış ve 15 dakika süreyle 3000 rpm'de santrifüj edilmişlerdir. Elde edilen ekstraktlar çalışmanın devamında kullanılmak üzere koyu renkli cam şişelere alınmış ve ağızları kapatılıp buzdolabında $+4{ }^{\circ} \mathrm{C}^{\prime}$ de muhafaza edilmiştir.

Çimlendirme öncesinde ayçiçeği, mısır ve soya tohumlarına yüzey sterilizasyonu uygulanmış ve tohumlar sodyum hipoklorit ( $\mathrm{NaClO}, \% 5)$ çözeltisinde $10 \mathrm{~d}$ bekletildikten (Uyanık ve ark., 2014) sonra dört kez saf suyla yıkanıp filtre kâğıdında kurutulmuştur. İçlerine çift kat Whatman No.1 filtre kâğıtları konulmuş petri kapları tohum ekiminden önce $115^{\circ} \mathrm{C}^{\prime}$ de etüvde sterilize edildikten sonra içlerine 20'şer tohum konulmuştur. Petri kaplarına \%0 (kontrol, distile su), \%5, \%10 ve \%20'lik yaprak ekstraktlarından 10 $\mathrm{ml}$ ilave edilerek iklim odasında 6 saat ışık/ 8 saat karanlıkta $22{ }^{\circ} \mathrm{C}$ sıcaklıkta bekletilmiştir.

Test bitkileri olan mısır, soya ve ayçiçeği için, Tesadüf Parsellerinde faktöriyel deneme tertibinde 4 tekerrürlü çimlendirme denemeleri yürütülmüştür. Denemelerde uygulama olarak 4 yaprak ektraktı (karalahana, ısırgan, sarı ve mor çiçekli ormangülü) ve $4 \mathrm{doz}(0, \% 5, \% 10$ ve \%20) yer almıştır. Tohumlarda $2 \mathrm{~mm}$ kökçük çıkışı çimlenme kriteri olarak kabul edilmiş ve 14 . sün sonunda çimlenme yüzdesi, kökçük ve sürgün uzunluğu ve ağırlığı tespit edilmiştir (Sivritepe, 2012). Elde edilen veriler, deneme desenine göre varyans analizine tabi tutulmuş ve ortalamalar arasındaki farklılıklar Tukey testiyle belirlenmiştir. Varyans analizinden önce, veriler arasında çok sayıda sıfır değeri yer aldığı için, tüm verilere $\mathrm{VX}+1$ transformasyonu uygulanmış (Yurtsever, 1984) ve istatistiki analizler Minitab 17 paket programı kullanılarak yapılmıştır.

\section{Bulgular ve Tartışma}

Isırgan, karalahana, mor çiçekli ve sarı çiçekli ormangülü yaprak ekstraktlarının mısır, ayçiçeği ve soya tohumlarının çimlenmesi ve fide gelişimi üzerine allelopatik etkilerinin incelendiği bu araştırmadan elde edilen bulgular test bitkileri esas alınarak özetlenmiştir. Yaprak ekstraktlarının çimlenme ve fide gelişimini engelleyici etkisi, [(kontrol-ekstrakt/kontrol) x 100] formülü uyarınca hesaplanmıştır.
Mısır tohumlarının çimlenme oranı, kökçük ve sürgün uzunluğu ile kökçük ve sürgün ağırlığı ekstrakt kaynağı ve ekstrak dozuna göre önemli farklılıklar göstermiştir (Çizelge 1). Çimlenme ve fide gelişimi üzerine en yüksek engelleyici etki ısırgan yaprak özütünden alınmış ve bunu karalahana, mor ve sarı çiçekli ormangülleri izlemiştir. Isırgan ve karalahana yaprak özütleri, kontrol tohumlarına göre mısır tohumlarının çimlenmesini sırasıyla ortalama $\% 49.7$ ve \%18.2 oranlarında engellemişlerdir. Isırgan ve karalahananın engelleyici etkisi sürgün gelişimine göre kökçük gelişiminde daha yüksektir. Isırgan ve karalahana yaprak özütlerinin kökçük ve sürgün gelişimini engelleyici etkisi sırasıyla \%47.4-68.1 ve \%18.2-49.0 arasında değişmektedir. Buna karşılık mor çiçekli ormangülü yaprak ekstraktı mısır tohumlarının çimlenmesinde \%1.0 civarında bir azalamaya yol açarken, sarı çiçekli ormangülü ekstraktı çimlenmeyi ortalama \%1.6 oranında arttırmıştır. Benzer şekilde, sarı ve mor çiçekli ormangüllerinin kökçük ve sürgün gelişimindeki engelleyici etkisi ısırgan ve karalahanaya göre daha düşüktür. Bütün bitkilerde ekstrakt dozu arttıkça çimlenme oranı, kökçük ve sürgün gelişimi de önemli derecede azalmıştır. Nitekim \%5'lik ekstrak dozunda çimlenme oranı ve fide gelişimi kontrol uygulamasına göre \%11.4-53.1 arasında azalırken, \%20'lik ekstrak dozunda azalma oranları \%36.376.11 seviyelerine yükselmiştir. İncelenen özelliklerde ekstrak kaynağı $x$ ekstrakt dozu interaksiyonu istatistiki olarak önemli çıkmıştır (Çizelge 1). Buna göre, artan ekstrak dozunun çimlenme oranı ve fide gelişimi üzerine etkisinin ekstrak kaynağına göre önemli derecede değiştiği anlaşılmaktadır. Doz artışının engelleyici etkisi özellikle ısırganda daha belirgindir. Isırgan yaprak özütünün $\% 5^{\prime}$ lik ve $\% 10^{\prime}$ luk dozları çimlenmeyi sırasıyla \%44.2 ve \%54.5 azaltmış, \%20'lik ekstrakt dozunda ise hiçbir tohum çimlenmemiştir. Buna karşılık, karalahana yaprak ekstraktının \%5, \%10 ve \%20'lik dozlarında kontrole göre çimlenmedeki azalma sırasıyla \%6.5, \%22.1 ve \%44.2 olarak gerçekleşmiştir.

Isırgan, karalahana, mor ve sarı çiçekli ormangülü yaprak ekstraktları uygulanan soya tohumlarında çimlenme oranı ile kökçük ve sürgün gelişmesi ekstrakt kaynağı ve ekstrak dozuna göre önemli farklılıklar göstermiştir (Çizelge 2). Diğer taraftan, ekstrak kaynağı $x$ ekstrakt dozu interaksiyonunun bütün özelliklerde istatistiki olarak önemli çıkması, ekstrakt dozunun çimlenme ve fide gelişimi üzerine etkisinin ekstrakt kaynağına göre farklı olduğunu ifade etmektedir. Bütün ekstrakt tiplerinde doz artışına paralel olarak çimlenme oranı ve fide gelişimi önemli derecede azalmıştır. Soya tohumlarında çimlenme ve fide 
gelişimi üzerine en yüksek engelleyici etkiyi ısırgan yaprak özütü göstermiş ve bunu karalahana yaprak özütü izlemiştir. Isırgan ve karalahana yaprak ekstraktları, kontrol uygulamasına göre, soya tohumlarının çimlenme ve fide gelişimini çok önemli ölçüde engellemiş, ısırganın \%10 ve \%20'lik dozlarıyla karalahananın \%20'lik dozunda soya tohumlarında çimlenme ve fide gelişimi görülmemiştir (Çizelge 2). Ayrıca ısırgan ve karalahana yaprak özütlerinin \%5'lik dozunda çimlenme oranında sırasıyla $\% 86.8$ ve $\% 42.9^{\prime}$ lık azalmalar kaydedilmiştir. Isırgan ve karalahananın engelleyici etkisi kökçük uzunluğu ve ağırlığında, sürgün uzunluğu ve ağırlığına göre daha yüksektir. Isırgan ve karalahananın tersine mor ve sarı çiçekli ormangülü yaprak özütleri soya tohumlarında çimlenme oranını artırmış ve sarı çiçekli ormangülünün \%20'lik dozunda çimlenme oranı \%100 olmuştur. Buna karşılık, mor ve sarı çiçekli ormangülü yaprak özütleri kökçük ve sürgün gelişmesi üzerine genellikle engelleyici etkide bulunmuşlardır.

Çizelge 1. Farklı dozlarda ısırgan, karalahana, mor çiçekli ormangülü ve sarı çiçekli ormangülü yaprak ekstraktları uygulanan mısır tohumlarının çimlenme oranı, kökçük ve sürgün uzunluğu ile kökçük ve sürgün ağırlığı.

\begin{tabular}{|c|c|c|c|c|c|}
\hline \multirow{2}{*}{ Ekstrakt dozu (\%) } & \multicolumn{5}{|c|}{ Ekstrakt kaynağı } \\
\hline & Isırgan & Karalahana & $\begin{array}{l}\text { Mor çiçekli } \\
\text { ormangülü }\end{array}$ & $\begin{array}{l}\text { Sarı çiçekli } \\
\text { ormangülü }\end{array}$ & Doz ortalaması \\
\hline \multicolumn{6}{|c|}{ Çimlenme oranı (\%) } \\
\hline 0 (kontrol) & $96.25 a^{*}$ & $96.25 \mathrm{a}$ & $96.25 \mathrm{a}$ & $96.25 \mathrm{a}$ & $96.25 A^{*}$ \\
\hline 5 & $53.75 \mathrm{bc}$ & $90.00 \mathrm{a}$ & $98.50 \mathrm{a}$ & $98.75 \mathrm{a}$ & $85.25 \mathrm{~B}$ \\
\hline 10 & $43.75 \mathrm{c}$ & $75.00 \mathrm{ab}$ & $93.75 a$ & $97.50 \mathrm{a}$ & $77.50 \mathrm{~B}$ \\
\hline 20 & 0.00 & $53.75 \mathrm{bc}$ & $92.75 a$ & $98.75 a$ & $61.31 \mathrm{C}$ \\
\hline Ekstrakt ortalaması & $48.44 C^{*}$ & $78.75 \mathrm{~B}$ & $95.31 \mathrm{~A}$ & $97.81 \mathrm{~A}$ & \\
\hline \multicolumn{6}{|c|}{ Kökçük uzunluğu (mm) } \\
\hline 0 (kontrol) & $118.24 a^{*}$ & $118.24 \mathrm{a}$ & $118.24 \mathrm{a}$ & $118.24 \mathrm{a}$ & $118.24 A^{*}$ \\
\hline 5 & $19.30 \mathrm{f}$ & $101.50 \mathrm{ab}$ & $37.05 \mathrm{df}$ & $81.17 \mathrm{ac}$ & $59.75 \mathrm{~B}$ \\
\hline 10 & $13.21 \mathrm{f}$ & 21.97 ef & $35.20 \mathrm{df}$ & $57.47 \mathrm{bc}$ & $31.21 \mathrm{C}$ \\
\hline 20 & 0.00 & $14.22 \mathrm{f}$ & $51.08 \mathrm{ce}$ & 47.70 ce & $28.25 \mathrm{C}$ \\
\hline Ekstrakt ortalaması & $37.69 \mathrm{C}^{*}$ & $63.98 \mathrm{~B}$ & $60.395 \mathrm{~B}$ & $76.14 \mathrm{~A}$ & \\
\hline \multicolumn{6}{|c|}{ Sürgün uzunluğu (mm) } \\
\hline 0 (kontrol) & $25.05 a^{*}$ & $25.05 \mathrm{ab}$ & $25.05 a b$ & $25.05 a b$ & $25.05 A^{*}$ \\
\hline 5 & $12.54 \mathrm{~b}$ & $23.75 a b$ & $20.07 \mathrm{ab}$ & $20.92 a b$ & $19.32 \mathrm{~B}$ \\
\hline 10 & $13.31 \mathrm{ab}$ & $16.32 \mathrm{ab}$ & $21.15 \mathrm{ab}$ & $17.07 \mathrm{ab}$ & $16.96 \mathrm{~B}$ \\
\hline 20 & 0.00 & $14.55 \mathrm{ab}$ & $16.90 \mathrm{ab}$ & $22.00 \mathrm{ab}$ & $13.36 \mathrm{~B}$ \\
\hline Ekstrakt ortalaması & $12.73 \mathrm{~B}^{*}$ & $19.92 \mathrm{~A}$ & $20.79 \mathrm{~A}$ & $21.26 \mathrm{~A}$ & \\
\hline \multicolumn{6}{|c|}{ Kökçük ağırlığı (mg) } \\
\hline 0 (kontrol) & $59.59 a^{*}$ & $59.59 \mathrm{a}$ & 59.59 a & $59.59 \mathrm{a}$ & $59.59 A^{*}$ \\
\hline 5 & $12.32 \mathrm{df}$ & $44.72 a b$ & 21.37 be & $33.37 \mathrm{ac}$ & $27.94 \mathrm{~B}$ \\
\hline 10 & 8.40 eg & $12.40 \mathrm{df}$ & 19.87 ce & $24.65 \mathrm{bd}$ & $16.33 \mathrm{C}$ \\
\hline 20 & 0.00 & $4.85 \mathrm{fg}$ & $27.60 \mathrm{bd}$ & $24.85 \mathrm{bd}$ & $14.32 \mathrm{C}$ \\
\hline Ekstrakt ortalaması & $20.08 \mathrm{~B}^{*}$ & $30.39 \mathrm{AB}$ & $32.11 \mathrm{AB}$ & $35.61 \mathrm{~A}$ & \\
\hline \multicolumn{6}{|c|}{ Sürgün ağırlığı (mg) } \\
\hline 0 (kontrol) & $81.45 a^{*}$ & $81.45 \mathrm{a}$ & $81.45 \mathrm{a}$ & $81.45 \mathrm{a}$ & $81.45 \mathrm{~A}^{*}$ \\
\hline 5 & $47.16 \mathrm{~b}$ & $81.38 \mathrm{a}$ & $62.17 \mathrm{a}$ & $85.60 \mathrm{a}$ & $69.08 \mathrm{~B}$ \\
\hline 10 & $42.75 \mathrm{~b}$ & $53.55 a b$ & $74.57 a$ & $58.02 \mathrm{a}$ & $57.22 \mathrm{~B}$ \\
\hline 20 & 0.00 & $45.77 \mathrm{~b}$ & $65.97 a$ & $72.05 \mathrm{a}$ & $45.95 \mathrm{C}$ \\
\hline Ekstrakt ortalaması & $42.84 \mathrm{~B}^{*}$ & $65.54 \mathrm{~A}$ & $71.04 \mathrm{~A}$ & $74.28 \mathrm{~A}$ & \\
\hline
\end{tabular}

*: Aynı harfe gösterilen ortalamalar arasında istatistiki olarak önemli $(P<0.05)$ fark yoktur 
Çizelge 2. Farklı dozlarda ısırgan, karalahana, mor çiçekli ormangülü ve sarı çiçekli ormangülü yaprak ekstraktları uygulanan soya tohumlarının çimlenme oranı, kökçük ve sürgün uzunluğu ile kökçük ve sürgün ağırlığı.

\begin{tabular}{|c|c|c|c|c|c|}
\hline \multirow[b]{2}{*}{ Ekstrakt dozu (\%) } & \multicolumn{5}{|c|}{ Ekstrakt kaynağı } \\
\hline & Isırgan & Karalahana & $\begin{array}{l}\text { Mor çiçekli } \\
\text { ormangülü }\end{array}$ & $\begin{array}{l}\text { Sarı çiçekli } \\
\text { ormangülü }\end{array}$ & Doz ortalaması \\
\hline \multicolumn{6}{|c|}{ Çimlenme oranı (\%) } \\
\hline 0 (kontrol) & $85.31 a^{*}$ & $85.31 \mathrm{ab}$ & $85.31 \mathrm{ab}$ & $85.31 \mathrm{a}$ & $85.31 \mathrm{~A}^{*}$ \\
\hline 5 & $11.25 \mathrm{~cd}$ & $48.75 \mathrm{bc}$ & $96.25 \mathrm{a}$ & $98.78 \mathrm{a}$ & $63.76 \mathrm{~B}$ \\
\hline 10 & 0.00 & $27.50 \mathrm{bd}$ & $92.50 \mathrm{a}$ & $73.75 \mathrm{ac}$ & $48.44 \mathrm{C}$ \\
\hline 20 & 0.00 & 0.00 & $73.75 \mathrm{ac}$ & $100.00 \mathrm{a}$ & $43.44 \mathrm{C}$ \\
\hline Ekstrakt ortalaması & $24.14 \mathrm{~B}^{*}$ & $40.39 \mathrm{~B}$ & $86.95 \mathrm{~A}$ & $89.46 \mathrm{~A}$ & \\
\hline \multicolumn{6}{|c|}{ Kökçük uzunluğu (mm) } \\
\hline 0 (kontrol) & $80.36 a^{*}$ & $80.36 \mathrm{a}$ & $80.36 \mathrm{ab}$ & $80.36 \mathrm{ab}$ & $80.36 A^{*}$ \\
\hline 5 & $4.59 \mathrm{~cd}$ & $24.12 \mathrm{bd}$ & $66.35 \mathrm{ab}$ & $73.55 \mathrm{ab}$ & $42.15 \mathrm{~B}$ \\
\hline 10 & 0.00 & $25.92 \mathrm{abd}$ & $28.22 \mathrm{ad}$ & $66.32 \mathrm{ac}$ & $30.11 \mathrm{~B}$ \\
\hline 20 & 0.00 & 0.00 & $40.60 \mathrm{ad}$ & $81.80 a b$ & $30.60 \mathrm{~B}$ \\
\hline Ekstrakt ortalaması & $21.24 \mathrm{C}^{*}$ & $32.60 \mathrm{BC}$ & $53.73 \mathrm{AB}$ & $75.51 \mathrm{~A}$ & \\
\hline \multicolumn{6}{|c|}{ Sürgün uzunluğu (mm) } \\
\hline 0 (kontrol) & $20.23 a^{*}$ & $20.23 \mathrm{a}$ & $20.23 \mathrm{a}$ & $20.23 \mathrm{a}$ & $20.23 A^{*}$ \\
\hline 5 & $8.70 \mathrm{ab}$ & $19.97 \mathrm{a}$ & $11.67 \mathrm{ab}$ & $23.67 \mathrm{a}$ & $16.00 \mathrm{~B}$ \\
\hline 10 & 0.00 & $11.90 \mathrm{ab}$ & $20.87 a$ & $18.95 \mathrm{a}$ & $12.93 \mathrm{~B}$ \\
\hline 20 & 0.00 & 0.00 & $9.10 a b$ & $21.15 \mathrm{a}$ & $7.56 \mathrm{C}$ \\
\hline Ekstrakt ortalaması & $7.23 C^{*}$ & $13.02 \mathrm{BC}$ & $15.47 \mathrm{AB}$ & $21.00 \mathrm{~A}$ & \\
\hline \multicolumn{6}{|c|}{ Kökçük ağırlığı (mg) } \\
\hline 0 (kontrol) & $60.10 a^{*}$ & $60.10 \mathrm{a}$ & $60.10 \mathrm{a}$ & $60.10 \mathrm{a}$ & $60.10 A^{*}$ \\
\hline 5 & $2.70 \mathrm{de}$ & $13.82 \mathrm{ce}$ & $47.97 \mathrm{ac}$ & $37.95 \mathrm{ad}$ & $25.61 \mathrm{~B}$ \\
\hline 10 & 0.00 & $16.87 \mathrm{ce}$ & 23.92 be & $42.65 \mathrm{ae}$ & $20.86 \mathrm{~B}$ \\
\hline 20 & 0.00 & 0.00 & 35.00 ae & $49.67 \mathrm{ac}$ & $21.17 \mathrm{~B}$ \\
\hline Ekstrakt ortalaması & $15.70 \mathrm{C}^{*}$ & $22.70 \mathrm{BC}$ & $41.75 \mathrm{AB}$ & $47.59 \mathrm{~A}$ & \\
\hline \multicolumn{6}{|c|}{ Sürgün ağırlığı (mg) } \\
\hline 0 (kontrol) & $63.23 \mathrm{a}^{*}$ & $63.23 \mathrm{a}$ & $63.23 \mathrm{a}$ & $63.23 \mathrm{a}$ & $63.23 A^{*}$ \\
\hline 5 & $30.02 a b$ & $40.57 \mathrm{a}$ & $27.05 \mathrm{~b}$ & $69.20 \mathrm{a}$ & $41.71 \mathrm{BC}$ \\
\hline 10 & 0.00 & $37.12 \mathrm{ab}$ & $54.22 \mathrm{a}$ & $52.35 a$ & $35.92 \mathrm{~B}$ \\
\hline 20 & 0.00 & 0.00 & $29.55 b$ & $60.67 \mathrm{a}$ & $22.55 \mathrm{C}$ \\
\hline Ekstrakt ortalaması & $23.31 \mathrm{C}^{*}$ & $35.23 \mathrm{BC}$ & $43.51 \mathrm{AB}$ & $61.36 \mathrm{~A}$ & \\
\hline
\end{tabular}

*: Aynı harfe gösterilen ortalamalar arasında istatistiki olarak önemli $(P<0.05)$ fark yoktur

Ayçiçeği tohumlarına uygulanan yaprak özütlerinin çimlenme ve fide gelişimi üzerine etkisi bitki türlerine göre farklı olmakla birlikte, genelde bütün yaprak ekstraktları çimlenme ve fide gelişimini engellemiştir (Çizelge 3 ). Isırgan ve karalahananın \%5 ve \%10'luk dozlarında ayçiçeği tohumlarının çimlenmesi \%82.4-86.4 arasında azalmış, \%20'lik dozda ise çimlenme ve fide gelişimi görülmemiştir. Buna karşılık, mor ve sarı çiçekli ormangülü yaprak özütlerinin \%20'lik dozunda tohumlarının çimlenmesindeki azalmalar \%39.2 ve \%47.3 oranlarında gerçekleşmiştir. Fide gelişimi ile ilgili özelliklerde ısırgan ve karalahana ekstraktlarının engelleyici etkisi mor ve sarı çiçekli ormangüllerine göre daha fazla olmuştur. Isırganın
\%5 ve \%10'lık dozlarında \%12.50-13.75 oranlarında çimlenme gerçekleşmiş fakat 14 günlük deneme sonunda kökçük tamamen çürüdüğü için, kökçük uzunluğu ve ağırlığı belirlenememiştir. Karalahana yaprak ekstraktının \%10'luk dozunda kökçük ve sürgün gelişmesi çok önemli derecede engellenmiş, neredeyse yok denecek seviyeye düşmüştür. Mor ve sarı çiçekli ormangülünün \%5'lik dozunda bazı özelliklerde kontrole göre artışlar söz konusudur. Genel olarak bütün yaprak özütlerinin engelleyici etkisi kökçük gelişmesinde, sürgün gelişmesine göre daha belirgindir.

Yaprak ekstraktlarının uygulandığı mısır, soya ve ayçiçeği tohumlarında çimlenme ve fide gelişimi üzerine en yüksek engelleyici etkiyi ısırgan 
yapmış, bunu karalahana, mor çiçekli orman gülü ve sarı çiçekli orman gülü izlemiştir. Sarı çiçekli ormangülü yaprak ekstraktının bütün dozları ve mor çiçekli orman gülünün \%5'lik dozunda mısır ve soya tohumlarının çimlenme yüzdesi ekstrakt uygulanmayan tohumlara göre artmıştır. Bütün test bitkilerinde, özellikle ısırgan ve karalahana olmak üzere, bütün yaprak ekstraktlarının engelleyici etkisinin kökçük uzunluğu ve ağırlığında sürgün uzunluğu ve ağırlığına oranla daha fazla olduğu dikkati çekmektedir. Bu bulguyu destekler mahiyette, Türkiye'deki aktarlardan temin edilen 55 familyaya ait 125 bitki türünün allelopatik potansiyelinin değerlendirildiği bir çalışmada (Ozkan ve ark., 2019) marul bitkisinde kök gelişmesinin, sürgün gelişmesine oranla, daha fazla engellendiği bildirilmektedirler.

Çizelge 3. Farklı dozlarda ısırgan, karalahana, mor çiçekli ormangülü ve sarı çiçekli ormangülü yaprak ekstraktları uygulanan ayçiçeği tohumlarının çimlenme oranı, kökçük ve sürgün uzunluğu ile kökçük ve sürgün ağırlığı.

\begin{tabular}{|c|c|c|c|c|c|}
\hline \multirow[b]{2}{*}{ Ekstrakt dozu (\%) } & \multicolumn{5}{|c|}{ Ekstrakt kaynağı } \\
\hline & Isırgan & Karalahana & $\begin{array}{l}\text { Mor çiçekli } \\
\text { ormangülü }\end{array}$ & $\begin{array}{l}\text { Sarı çiçekli } \\
\text { ormangülü }\end{array}$ & Doz ortalaması \\
\hline \multicolumn{6}{|c|}{ Çimlenme oranı (\%) } \\
\hline 0 (kontrol) & $92.50 a^{*}$ & $92.50 \mathrm{a}$ & $92.50 \mathrm{a}$ & $92.50 \mathrm{a}$ & $92.50 \mathrm{~A}^{*}$ \\
\hline 5 & $12.50 \mathrm{ce}$ & $16.25 \mathrm{bd}$ & $92.50 \mathrm{a}$ & $66.25 \mathrm{a}$ & $46.87 \mathrm{~B}$ \\
\hline 10 & $13.75 \mathrm{de}$ & 13.75 be & $50.00 \mathrm{ac}$ & $65.00 \mathrm{a}$ & $35.62 \mathrm{BC}$ \\
\hline 20 & 0.00 & 0.00 & $56.25 a b$ & $48.75 \mathrm{ad}$ & $26.25 \mathrm{C}$ \\
\hline Ekstrakt ortalaması & $29.69 B^{*}$ & $30.62 \mathrm{~B}$ & $72.81 \mathrm{~A}$ & $68.12 \mathrm{~A}$ & \\
\hline \multicolumn{6}{|c|}{ Kökçük uzunluğu (mm) } \\
\hline 0 (kontrol) & $18.79 a^{*}$ & $18.79 \mathrm{a}$ & $18.79 \mathrm{a}$ & $18.79 \mathrm{a}$ & $18.79 A^{*}$ \\
\hline 5 & 0.00 & $6.02 b c$ & $19.60 \mathrm{a}$ & $21.25 \mathrm{a}$ & $11.72 \mathrm{~B}$ \\
\hline 10 & 0.00 & $1.00 \mathrm{c}$ & $14.45 \mathrm{a}$ & 17.07 a & $8.13 \mathrm{BC}$ \\
\hline 20 & 0.00 & 0.00 & $13.65 \mathrm{ab}$ & $7.76 \mathrm{bc}$ & $5.35 \mathrm{C}$ \\
\hline Ekstrakt ortalaması & $4.70 \mathrm{~B}^{*}$ & $6.45 \mathrm{~B}$ & $16.62 \mathrm{~A}$ & $16.22 \mathrm{~A}$ & \\
\hline \multicolumn{6}{|c|}{ Sürgün uzunluğu (mm) } \\
\hline 0 (kontrol) & $23.48 a^{*}$ & $23.48 \mathrm{a}$ & $23.48 \mathrm{a}$ & $23.48 \mathrm{a}$ & $23.48 A^{*}$ \\
\hline 5 & $3.70 \mathrm{de}$ & $14.32 \mathrm{bd}$ & $25.75 \mathrm{a}$ & $29.15 \mathrm{a}$ & $18.23 \mathrm{~B}$ \\
\hline 10 & $2.52 \mathrm{de}$ & $3.82 \mathrm{de}$ & $17.85 a b$ & $24.17 \mathrm{a}$ & $12.09 \mathrm{BC}$ \\
\hline 20 & 0.00 & 0.00 & $18.30 \mathrm{ab}$ & $14.13 \mathrm{bd}$ & $8.11 \mathrm{C}$ \\
\hline Ekstrakt ortalaması & $7.42 \mathrm{~B}^{*}$ & $10.11 \mathrm{~B}$ & $21.34 \mathrm{~A}$ & $22.73 \mathrm{~A}$ & \\
\hline \multicolumn{6}{|c|}{ Kökçük ağırlığı (mg) } \\
\hline 0 (kontrol) & $35.35 a *$ & $35.35 \mathrm{a}$ & $35.35 \mathrm{a}$ & $35.35 \mathrm{a}$ & $35.35 \mathrm{~A}^{*}$ \\
\hline 5 & 0.00 & $7.45 \mathrm{bd}$ & $21.52 a b$ & $23.98 \mathrm{ab}$ & $13.24 \mathrm{~B}$ \\
\hline 10 & 0.00 & $0.35 \mathrm{~d}$ & $16.57 \mathrm{ad}$ & $18.82 \mathrm{ac}$ & $8.93 \mathrm{BC}$ \\
\hline 20 & 0.00 & 0.00 & $9.47 \mathrm{bd}$ & $11.77 \mathrm{bd}$ & $5.31 \mathrm{C}$ \\
\hline Ekstrakt ortalaması & $8.84 \mathrm{~B}^{*}$ & $10.79 \mathrm{~B}$ & $20.73 \mathrm{~A}$ & $22.48 \mathrm{~A}$ & \\
\hline \multicolumn{6}{|c|}{ Sürgün ağırlığı (mg) } \\
\hline 0 (kontrol) & $78.12 a^{*}$ & $78.12 \mathrm{a}$ & $78.12 \mathrm{a}$ & $78.12 \mathrm{a}$ & $78.12 A^{*}$ \\
\hline 5 & $2.17 \mathrm{~cd}$ & $52.27 \mathrm{ad}$ & $73.42 \mathrm{a}$ & $82.67 \mathrm{a}$ & $52.63 \mathrm{~B}$ \\
\hline 10 & $5.32 \mathrm{bd}$ & $0.80 \mathrm{~cd}$ & $41.17 \mathrm{ab}$ & $75.67 \mathrm{a}$ & $30.74 \mathrm{BC}$ \\
\hline 20 & 0.00 & 0.00 & $49.82 \mathrm{ab}$ & $47.67 \mathrm{ad}$ & $23.12 \mathrm{C}$ \\
\hline Ekstrakt ortalaması & $21.40 \mathrm{~B}^{*}$ & $32.80 \mathrm{~B}$ & $60.63 \mathrm{~A}$ & $71.03 \mathrm{~A}$ & \\
\hline
\end{tabular}

*: Aynı harfe gösterilen ortalamalar arasında istatistiki olarak önemli $(\mathrm{P}<0.05)$ fark yoktur

Literatürde ısırgan, karalahana ve mor ve sarı çiçekli ormangülünün allelopatik etkilerine yönelik her hangi bir çalışmaya rastlanılmadığı için, bu çalışmadan elde edilen bulguların karşılaştırılmalı değerlendirmesi yapılamamıştır. Brassicaceae familyası türlerinin yabancı otlar ve kültür bitkilerinin çimlenme ve büyüme-gelişmesi üzerine allopatik etkilerinin yüksek olduğu ve bunun glukosinolatlar ile bunların parçalanma ürünü olan biyokimyasallardan (özellikle izotiyosiyonatlar) kaynaklandığı bilinmektedir (Fahey ve ark., 2001; Rehman ve ark., 2019). Brassica türlerinde glukosinolat bileşiklerinin miktarı ve içeriği bitki türü, bitki organı, bitkinin gelişme dönemi ve çevre koşullarına göre değişmektedir (Bhandari ve ark., 2015). Bu 
kapsamda şalgam (Brassica campestris L. subsp. rapa), kolza (Brassica napus L. ssp. oleifera DC.), turp (Raphanus sativus L.), lahana (Brassica oleracea) ve brokoli (Brassica oleracea var. italica) gibi Brassica türlerinin allelopatik potansiyelini gösteren bazı çalışmalar bulunmaktadır (Oleszek, 1987; Tawaha ve Turk, 2003; Üremiş ve ark., 2005; Üremiş ve ark., 2009; Dişli ve Nemli, 2014). Bununla birlikte literatürde karalahana (Brassica oleracea var. viridis)'nın allelopatik etkisini gösteren bir araştırmaya rastlanılmamıştır.

Ülkemizin doğal florasında yaygın olan ısırgan, içerdiği çeşitli farmakolojik etkiye sahip biyokimyasallar sayesinde yıllardır tıbbi amaçlı olarak kullanılmaktadır ve ayrıca hafif, uzun ve sağlam lifleriyle lif kaynağı olarak önem taşımaktadır (Ayan ve ark. 2006; Gülçin ve ark., 2004). Isırganın yaprak yüzeyindeki tüylerinde formik asit, serotonin ve histamin gibi Isırgana yakıcı özellik kazandıran ve koruyucu etkisi olan bazı kimyasallar bulunmaktadır (Maaroufi ve ark., 2017). Öden ve ark. (2004) tarafından yürütülen bir çalışmada, tütün bitkisinde önemli olan orabanş zararlısına karşı yeşil gübre olarak ısırgan otu ekstraktı kullanılmış ve kontrol bitkilerinde \%38 olan orabanş görülme oranı, ısırgan otu ekstraktı uygulanan bitkilerde \%8.3'e kadar azalmıştır. Mor ve sarı çiçekli ormangülü yaprak ve çiçekleri grayanotoksin isimli alkaloit içerdikleri için tıbbi amaçlı olarak kullanıldıkları gibi aynı zamanda insan ve hayvanlarda zehirli etki yapabilirler (Avcı, 2004). Literatürde bazı Rhododendron türlerinin ( $R$. maximum, $R$. formasanum) içerdiği allelopatik biyokimyasallardan dolayı diğer bitkilerin gelişmesini engellediğini bildiren çalışmalar mevcuttur (Nilsen ve ark., 1999; Chou ve ark., 2010).

\section{Sonuç ve Öneriler}

Sonuç olarak, bu araştırmadan elde edilen bulgulara göre; özellikle ısırgan ve karalahana yaprak ekstraktlarının mısır, soya ve ayçiçeği tohumlarının çimlenmesi ve fide gelişmesi üzerine çok önemli seviyede engelleyici etkisinin olduğu belirlenmiştir. Bitki esktraktlarının çimlenme ve fide gelişimini engelleyici etkisi bütün test bitkilerinde ısırgan > karalahana > mor çiçekli orman gülü > sarı çiçekli ormangülü sıralamasını izlemiştir. Isırgan ve karalahananın \%20'lik dozunda ayçiçeği ve soya tohumlarında; ısırganın \%10'luk dozunda soya, \%20'lik dozunda mısır tohumlarında çimlenme ve fide gelişmesi görülmemiştir. Bu çalışma ısırgan ve karalahananın mısır, soya ve ayçiçeğinde tohumların çimlenmesi ve fide gelişimi üzerine engelleyici etkilerinin oldukça yüksek olduğunu göstermiştir. Bu bağlamda, ısırgan ve karalahananın allelopatik potansiyelinin tam olarak ortaya konulabilmesi ve etkili faktörlerin tanımlanabilmesi için tarla şartlarında kapsamlı araştırmaların yürütülmesi faydalı olacaktır.

$¥$ : Bu çalışma 1. yazarın yüksek lisans tezinden türetilmiştir.

Çıkar Çatışması Beyanı: Makale yazarları aralarında herhangi bir çıkar çatışması olmadığını beyan ederler.

Araştırmacıların Katkı Oranı Beyan Özeti: Yazarlar makaleye eşit oranda katkı sağlamış olduklarını beyan ederler.

\section{Kaynaklar}

Alam, S.M., Ala, S.A, Azmi A.R, Khan, M.A. ve Ansari, R. 2001. Allelopathy and its role in agriculture. Journal of Biological Sciences, 5: 308-315.

Arslan, M., Üremiş, i. ve Uludağ, A. 2005. Determining bio-herbicidal potential of rapeseed, radish and turnip extracts on germination inhibition of cutleaf groundcherry (Physalis angulata L.) Seeds. Journal of Agronomy, 4: 134-137.

Atak, M., Mavi, K. ve Uremis, I. 2016. Bio-herbicidal effects of oregano and rosemary essential oils on germination and seedling growth of bread wheat cultivars and weeds. Romanian Biotechnological Letters, 21: (1) 11149-11159.

Avcl, M. 2004. Ormangülleri (Rhododendron L.) ve Türkiye'deki doğal yayılışları. istanbul Üniversitesi Edebiyat Fakültesi Coğrafya Bölümü Coğrafya Dergisi, 12: 13-29.

Ayan, A.K., Çalışkan, Ö. ve Çırak, C. 2006. Isırgan otu (Urtica spp.)'nun ekonomik önemi ve tarımı. Ondokuz Mayıs Üniversitesi Ziraat Fakültesi Dergisi, 21 (3): 357-363.

Batish, D.R., Singh, H.P. ve Kaur, S. 2001. Crop allelopathy and its role in ecological agriculture. Journal of Crop Production, 4 (2): 121-161.

Bhadoria, P.B.S. 2011. Allelopathy: A natural way towards weed management. American Journal of Experimental Agriculture, 1 (1): 7-20.

Bhandari, S.R., Jo, J.S. ve Lee, J.G. 2015. Comparison of glucosinolate profiles in different tissues of nine brassica crops. Molecules, 20: 15827-15841.

Cheng, F. ve Cheng, Z. 2015. Research progress on the use of plant allelopathy in agriculture and the physiological and ecological 
mechanisms of allelopathy. Frontiers in Plant Science, 6: 1020.

Chou, S.C., Huang, C.H., Hsu, T.W., Wu, C.C. ve Chou, C.H. 2010. Allelopathic pPotential of Rhododendron formosanum Hemsl in Taiwan. Allelopathy Journal, 25 (1): 73-91.

Cummings, J.A., Parker, I.M. ve Gilbert, G.S. 2012. Allelopathy: A tool for weed management in forest restoration. Plant Ecology, 213: 1975-1989.

Dişli, Ö.G. ve Nemli, Y. 2014. Sinapis alba L. " nın (Akhardal) çimlenme ve gelişimine, bazı kültür bitkisi kök eksudatları ve yeşil gübrelerinin etkisi. Ege Üniversitesi Ziraat Fakültesi Dergisi, 51 (1): 13-22.

Duke, O.S. 2010. Allelopathy: Current status of research and future of the discipline: $A$ commentary. Allelopathy Journal, 25: 1730.

Fahey, J.W., Zalcmann, A.T. ve Talalay, P. 2001. The chemical diversity and distribution of glucosinolates and isothiocynates among plants. Phytochemistry, 56: 5-51.

Farooq, M., Bajwa, A.A., Cheema, S.A. ve Cheema, Z.A. 2013. Application of allelopathy in crop production. International Journal of Agriculture and Biology, 15: 1367-1378.

Farooq, M., Jabran, K., Cheema, Z.A., Wahid, A. ve Siddique, K.H. 2011. The role of allelopathy in agricultural pest management. Pest Management Science, 67: 493-506.

Fujii, Y., Parvez, S.S., Parvez, M.M., Ohmae, Y. ve lida, O. 2003. Screening of 239 medicinal plant species for allelopathic activity using the sandwich method. Weed Biology and Management, 3: 233-241.

Gülçin, İ., Küfrevioğlu, Ö.í., Münir, $O$. ve Büyükokuroğlu, M.E. 2004. Antioxidant, antimicrobial, antiulcer and analgesic activities of nettle (Urtica dioica L.). Journal of Ethnopharmacology, 90 (2-3): 205-215.

Gürsoy, M., Balkan, A. ve Ulukan, H. 2013. Bitkisel üretimde allelopati. Uludağ Üniversitesi Ziraat Fakültesi Dergisi, 27 (2): 115-122.

Maaroufi, L., Hossain, M.S., Tahril, W. ve Landoulsil, A. 2017. New insights of nettle (Urtica urens): Antioxidant and antimicrobial activities. Journal of Medicinal Plants Research, 11 (4): 73-86.

Macias, F.A., Molinillo, J.M.G., Varela, R.M., Galindo, J.C.G. 2007. Allelopathy -a natural alternative for weed control. Pest Management Science, 63 (4): 327-348.

Nilsen, E.T., Walker, J.F., Miller, O.K., Semones, S.W., Lei, T.T. ve Clinton, B.D. 1999.
Inhibition of seedling survival under Rhododendron maximum (Ericaceae): Could allelopathy be a cause? American Journal of Botany, 86 (11): 1597-1605.

Oleszek, W. 1987. Allelopathic effects of volatiles from some Cruciferae species on lettuce, barnyard grass and wheat growth. Plant and Soil, 102 (2): 271-273.

Ozkan, T.G.I., Urusak, E.A., Appiah, K.S. ve Fujii, Y. 2019. First broad screening of allelopathic potential of wild and cultivated plants in Turkey. Plants, 8: 532.

Önen, H., Özer, Z. ve Telci, í. 2002. Bioherbicidal effects of some plant essential oils on different weed species. Journal of Plant Diseases and Protection, 18: 597-605.

Rehman, S., Shahzad, B., Bajwa, A.A., Hussain, S., Rehman, A., Cheema, S.A., Abbas, T., Ali, A., Shah, L., Adkins, L. ve Peijin, L. 2019. Utilizing the allelopathic potential of brassica species for sustainable crop production. A review. Journal of Plant Growth Regulation, 38:343-356.

Singh, H.P., Daiz, B.R. ve Kohli, R.K. 2001. Allelopathy in agroecosystems. Journal of Crop Production, 4: 1-41.

Singh, H.P., Batish, D.R. ve Kohli, R.K. 2003. Allelopathic interactions and allelochemicals: New possibilities for sustainable weed management. Critical Reviews in Plant Sciences, 22: 239-311.

Sivritepe, H.Ö. 2012. Tohum gücünün değerlendirilmesi. Alatarım, 11 (2): 33-44.

Tawaha, A.M. ve Turk, M.A. 2003. Allelopathic effects of black mustard (Brassica nigra) on germination and growth of wild barley (Hordeum spontaneum). Journal of Agronomy \& Crop Science, 189; 298-303.

Trezzi, M.M., Vidal, R.A., Junior, A.A.B., Bittencourt, H.V.H. ve Filho, A.P.S.S. 2016. Allelopathy: driving mechanisms governing its activity in agriculture. Journal of Plant Interactions, 11 (1): 53-60.

Turker, A. ve Usta, C. 2006. Biological activity of some medicinal plants sold in Turkish health-food stores. Biotechnology \& Biotechnological Equipment, 20 (3): 105113.

Uludağ, A., Üremiş, İ., Arslan, M. ve Gözcü, D. 2006. Allelopathy studies in weed science in Turkey - A review. Journal of Plant Diseases and Protection, 20: 419-426.

Uyanık, M., Kara, Ş.M. ve Korkmaz, K. 2014. Bazı kışlık kolza (Brassica napus L.) çeşitlerinin çimlenme döneminde tuz stresine tepkilerinin belirlenmesi. Tarım Bilimleri Dergisi, 4 (20): 368-375. 
Üremiş, i., Arslan, M. ve Uludağ, A. 2005. Allelopathic effects of some brassica species on germination and growth of cutleaf ground-cherry (Physalis angulata L.). Journal of Biological Sciences, 5 (5): 661-665.

Üremiş, ì., Arslan, M., Uludağ, A. ve Sangün, M.K. 2009. Allelopathic potentials of residues of 6 brassica species on johnsongrass [Sorghum halepense (L.) Pers.]. African Journal of Biotechnology, 8 (15): 34973501.

Weston, L.A. ve Duke, S.O. 2003. Weed and crop allelopathy. Critical Reviews in Plant Sciences, 22 (3-4): 367-389.

Yurtsever N, 1984. Deneysel İstatistik Metotlar. Tarım Orman ve Köyişleri Bakanlığı, Köy Hizmetleri Genel Müdürlüğü Yayınları. Genel Yayın No: 121, Teknik Yayın No: 56, s.623, Ankara-Türkiye. 